\title{
Evaluation of Physiological Responses to Human Approach Manner in Pet Dogs
}

\author{
Megumi Fukuzawa*, Tsukasa Ema, Osamu Kai \\ Nihon University, College of Bioresource Sciences, Department of Animal Resource and Sciences, Fujisawa, \\ Japan \\ Email: "fukuzawa.megumi@nihon-u.ac.jp
}

Received 27 February 2016; accepted 24 April 2016; published 27 April 2016

Copyright (C) 2016 by authors and Scientific Research Publishing Inc.

This work is licensed under the Creative Commons Attribution International License (CC BY). http://creativecommons.org/licenses/by/4.0/

(c) () Open Access

\begin{abstract}
We used eye-surface temperature and heart rate as simple, noninvasive physiological indices to evaluate dogs' responses to an approaching person. Thirteen healthy pet dogs $(49.62 \pm 31.42$ months; $19.28 \pm 11.46 \mathrm{~kg}$ ) were recruited as subjects to investigate physiological responses to approach. We set up two types of approach (smiling and expressionless) by familiar or unfamiliar people of either sex, and all tests were recorded by video cameras. Eye temperature was measured with an infrared thermal camera image, and the dog was equipped with a heart-rate monitor during testing. There were temporal changes in heart rate, and response time differed between HR and eye temperature. Although it may be the one which has to control both a background of the dogs or observational environment, and the response time of each parameter needs to be considered, these two parameters should be useful for non-invasive monitoring of physiological states in dogs in various practical animal situations.
\end{abstract}

\section{Keywords}

Dog, Heart rate, Human Approach Manner, Eye Temperature

\section{Introduction}

Body temperature is affected by changes in emotions: for example, the temperature of the tail or limbs falls in association with phobic responses in rats [1]. Although body temperature is maintained within fixed limits by autonomic regulation and thermoregulatory behavior, the precise nature of each physiological response and behavioral action differs with changes in environmental temperature. Often the body temperature of animals is measured inside the rectum or an ear. However, because animals can feel pain during measurement in such re-

${ }^{*}$ Corresponding author. 
gions - not only from insertion of the measuring device but also from the restraint used — stress needs to be taken into consideration. Attention has therefore been given to thermography as a non-invasive and simple method of measuring body temperature.

Travain et al. evaluated eye temperature in dogs in a stressful situation using infrared thermography; they also suggested that infrared thermography may be a useful tool for investigating emotional psychogenic stress in dogs [2]. Although it is possible to measure eye temperature continuously [3], the activity level of the dog may affect the quality of the recorded images. Gauvin et al. reported that there was a low-amplitude circadian rhythm in telemetrically recorded core body temperatures in laboratory beagle dogs [4]. Our focus here was to measure eye temperature, not continuously but at intervals; we hypothesized that infrared thermography could be used effectively for this purpose in environment where it was not possible to collect data continuously.

Thermography detects the infrared rays emitted by the surface of an object and displays them as an image. Fukuzawa et al. reported that infrared thermography and ear temperature, and their interaction, were physical indices of the response of dogs to human approach. The skin-surface temperature of the dogs tested changed with the approach of humans, and a positive correlation was observed between ear temperature (as measured with a Vet-Temp Instant Ear Thermometer; Advanced Monitors Corporation, CA, USA) and eye-surface temperature (as measured with an infrared thermographic camera) [5].

Human approach likely affects the dogs' emotions and thus the temperature of the blood flowing through the subcutaneous issues. The heart circulates blood to the whole body and is controlled by both sympathetic and parasympathetic nerves. The sympathetic system works to protect an individual from the external world, and the parasympathetic system acts to maintain the individual. The heart rate (HR) is therefore an index of the balance between stimulation of the two types of autonomic nerves. For example, HR in sheep rises with transfer stress [6], and HR in dogs rises with aversive stimuli, such as the opening and closing of an umbrella, or noise at 110 to $120 \mathrm{~dB}$ [7]. Therefore, because HR rises with increasing stress, it is a useful objective index of behavioral state (i.e. of the excitement or stress relevant to sympathetic nerve stimulation). Our aim here was to evaluate the interaction between human approach manner and two noninvasive physiological indicators (infrared thermography and HR) in dogs.

\section{Materials and Methods}

\subsection{Dogs}

Thirteen healthy pet dogs ( 5 neutered females, 4 non-neutered females, and 4 castrated males) were recruited. There were 4 German shepherds, 2 miniature schnauzers, 1 Labrador retriever, 1 Golden retriever, 1 Border collie, 1 Shiba-inu, 1 Chihuahua, and 2 mixed-breed dogs. Ages ranged from 12 to 121 months $(49.62 \pm 31.42$ months), and body weights ranged from 4.5 to $39.7 \mathrm{~kg}(19.28 \pm 11.46 \mathrm{~kg})$. Seven $(38.57 \pm 25.25$ months $/ 23.29 \pm$ $8.01 \mathrm{~kg})$ out of thirteen dogs were only joined in a familiar people approach, and twelve dogs $(52.17 \pm 31.38$ months $/ 18.06 \pm 11.05 \mathrm{~kg}$ ) including new six dogs were joined in an unfamiliar people approach. The dogs had received basic obedience training from their owners or from the same female dog trainer before entering the study. These basic training periods depended on each dog. None of the dogs had a history of extreme aggressive or fearful responses toward people during their everyday lives. All owners or persons who regularly handled the dogs were informed and agreed to attend the study. On the day of the experiment, the dogs were kept individually in their own familiar kennels (see below for details) at the university during the day and were all handled equally. They returned to their own homes after finishing the experimental work. All dogs normally had contact with the outside environment and with humans during the daytime, but from $30 \mathrm{~min}$ before the start of the test their contact with unfamiliar humans was restricted to avoid excessive excitement.

\subsection{Approaching and Staying Persons}

Either a person familiar with the dog or a person unfamiliar with it made the approach. The familiar persons were two graduate students (in their 20s; one of either sex) who had looked after the dog for 3 months continuously during the daytime when it had stayed in its own kennel. The dogs regularly stayed at the university on weekdays and went home to their families at night and on the weekends. The unfamiliar persons were four graduate students (in their 20s; two males and females) who had not met or had contact with the dog in the past. On each of the two experimental days, one familiar female and male and one unfamiliar female and male (i.e. a 
total of four people) approached the dog in random order by using one of two randomly allocated approach manners (see below), giving a total of four trials each day.

\subsection{Experimental Environment}

For each test, a dog was brought from its day kennel at the university to the experimental room (floor dimensions $3.60 \times 5.75 \mathrm{~m}$, Figure 1), which was located next to the day kennels. The room temperature was controlled at $24.0^{\circ} \mathrm{C} \pm 1.5^{\circ} \mathrm{C}$.

\subsection{Test Procedure}

The handler, who was well known to the dogs, took off the lead and allowed the dog to search the experimental space freely. After the searching behavior (e.g. walking around the experimental space, sniffing the floor) had ended (about 3 to $5 \mathrm{~min}$ ), the handler put the lead back on and fitted a Polar HR monitor (RS800sd; Polar Electro Oy Vorp, Kempele, Finland) to the dog. The dog was then left to sit quietly beside the handler for 15 min so that we could obtain a baseline HR. All dogs were able to maintain a sitting posture with no major movement during the $15 \mathrm{~min}$.

After $15 \mathrm{~min}$, the first thermal eye images were recorded (T1) with an infrared thermographic camera (Nippon Avionics Co., Ltd, Tokyo, Japan) as a baseline eye image. The camera was positioned approximately $2.4 \mathrm{~m}$ from the dog. The maximum temperature was used in our data analysis.

The approach person entered the room and waited behind a wooden screen $(180 \times 180 \mathrm{~cm})$. The person then moved in front of the screen and called the dog's name once, maintaining eye contact with the dog. Two types of approach ("smiling" and "expressionless") were used. The approach person kept looking slightly above the dog's face and approached with either a smile ("smiling") or no expression ("expressionless"). The person stopped at the point where the dog seemed to be frightened or wary, finally moving forward to a distance of 70 $\mathrm{cm}$ from the dog within 2 min of stopping, at which time thermal images were recorded (T2). No dogs showed these behaviors during tests.

The handler stayed in his or her own fixed position next to the dog and did not present the dog with any stimuli (e.g. no pulling back on the leash or encouraging the dog to stay in position), even if the dog pulled on the leash after the approach began. The handler held the leash as neutrally as possible during testing; he or she did not look at the approaching person and did not encourage the dog to look at the approaching person. Images were recorded again $5 \mathrm{~min}$ after the person had stopped $70 \mathrm{~cm}$ from the $\operatorname{dog}$ (T3; i.e. the approaching person

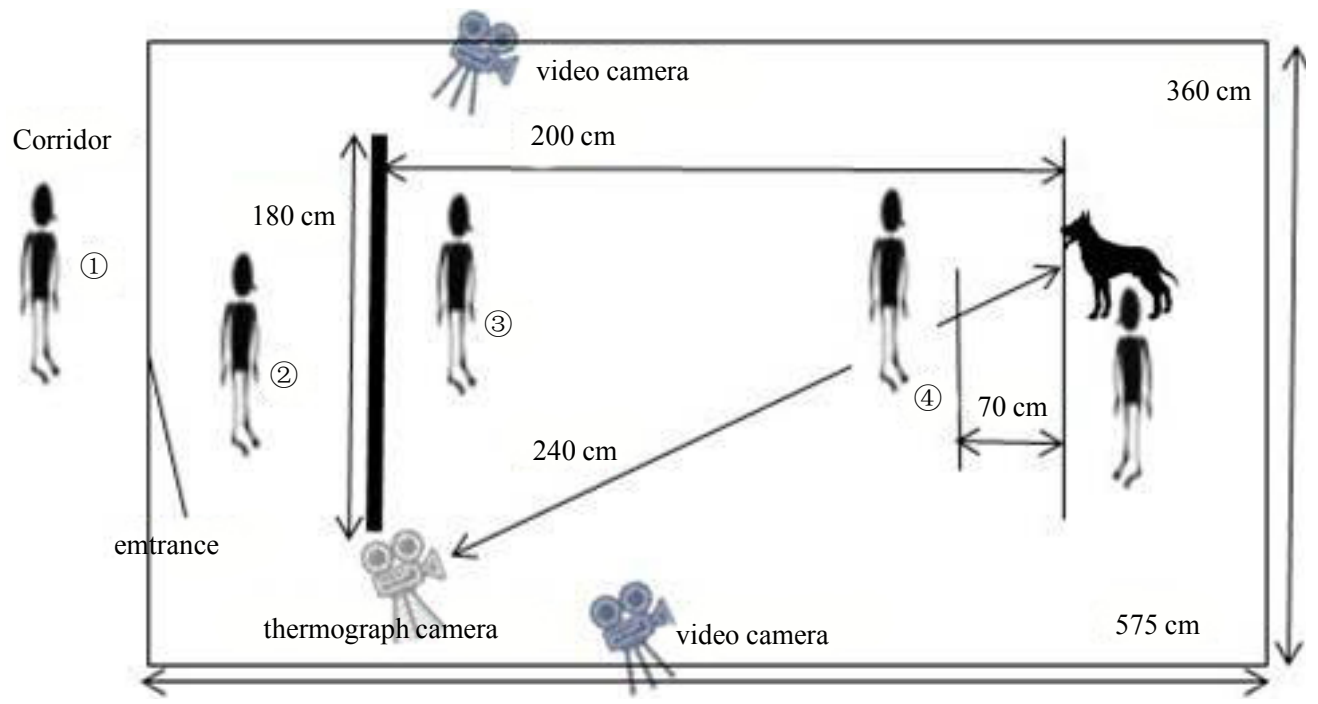

Figure 1. Observational environment. Two video cameras and an infrared thermography camera were installed. The operator stood beside the thermographic camera and the handler stood beside the dog. Before the test began, the approach person stood in the corridor (1); they then moved to stand facing the dog, which was sitting in a designated area $2 \mathrm{~m}$ away (2) - (4)). 
stayed in front of the dog until $3 \mathrm{~min}$ after T2), and then the approach person left the room immediately. The approach person continued to look slightly above the dog's head without moving his or her body, but did not look directly into the dog's eyes during this approximately 3 -min period of facing the dog. Final thermal images were recorded $5 \mathrm{~min}$ after the person had left the room (T4; i.e. $10 \mathrm{~min}$ after T1). Between T3 and T4, the handler stayed in his or her own fixed position, did not present any stimuli to the dog, and did not attempt to restrain the dog's behavior. This series of procedures was taken as one trial. The familiar person of each sex entered once a day. An unfamiliar person of each sex also entered once a day. The interval between trials was at least $30 \mathrm{~min}$, and the dog was put back into its kennel between trials. To prevent the possibility of habituation to the approach of an unfamiliar person, the two experimental days were separated by at least 1 month.

\subsection{Statistical Analysis}

The maximum eye temperature was used as a standard, and Avio PE Professional software (Nippon Avionics Co., Ltd, Tokyo, Japan) was used to analyze all thermal images. HR was recorded by using R-R interval data, and mean HR during each approach was used. The initial analysis used factorial measures analysis of variance (ANOVA) to assess the effect of approach manner, sex, and point of time on both eye temperature and HR. Post hoc Tukey's tests were used for pair-wise comparison of the means of each index when significant effects were found.

\section{Results}

\subsection{Eye-Surface Temperature}

There were no significant differences in eye-surface temperature between any of the time points in the case of either familiar or unfamiliar approaches, either smiling or expressionless (Table 1).

\subsection{Heart rate}

HR was significantly greater at T2 than at T1 and T4 in the case of both unfamiliar and familiar approaches (Tukey, $\mathrm{P}<0.05$ ). There were no other significant differences (Table 2).

\section{Discussion}

We examined the validity of using two physiological indicators (eye-surface temperature and HR) to determine the reactions of dogs to approaches by familiar or unfamiliar humans of either sex using different facial expressions.

Table 1. Average eye-surface temperature and standard deviations during each period, each condition.

\begin{tabular}{|c|c|c|c|c|c|c|}
\hline \multirow[b]{2}{*}{$\begin{array}{l}\text { Status of } \\
\text { person }\end{array}$} & \multirow[b]{2}{*}{$\begin{array}{l}\text { Approaching } \\
\text { manner }\end{array}$} & \multirow[b]{2}{*}{$\begin{array}{l}\text { Sex of } \\
\text { person }\end{array}$} & \multicolumn{4}{|c|}{ Eye-surface temperature $\left({ }^{\circ} \mathrm{C}\right)$} \\
\hline & & & T1 (Baseline) & $\begin{array}{c}\mathrm{T} 2 \text { (2min later after } \\
\text { approaching) }\end{array}$ & $\begin{array}{c}\mathrm{T} 3 \text { (3 min later } \\
\text { after T2) }\end{array}$ & $\begin{array}{c}\mathrm{T} 4 \text { (5 min later } \\
\text { after } \mathrm{T} 3)\end{array}$ \\
\hline \multirow{5}{*}{ Familiar } & Smiling & female & $34.04 \pm 0.78$ & $33.80 \pm 0.93$ & $33.90 \pm 0.62$ & $34.06 \pm 0.51$ \\
\hline & & male & $34.28 \pm 0.50$ & $34.25 \pm 0.67$ & $34.37 \pm 0.42$ & $34.39 \pm 0.42$ \\
\hline & Expressionless & female & $34.24 \pm 0.53$ & $34.20 \pm 0.37$ & $34.23 \pm 0.37$ & $34.29 \pm 0.28$ \\
\hline & & male & $34.15 \pm 0.32$ & $34.20 \pm 0.50$ & $34.39 \pm 0.33$ & $34.62 \pm 0.44$ \\
\hline & & & $\mathrm{T} 1$ & $\mathrm{~T} 2$ & $\mathrm{~T} 3$ & $\mathrm{~T} 4$ \\
\hline \multirow{4}{*}{ Unfamiliar } & Smiling & female & $33.78 \pm 0.57$ & $33.65 \pm 0.73$ & $33.72 \pm 0.71$ & $33.85 \pm 0.68$ \\
\hline & & male & $33.55 \pm 0.71$ & $33.52 \pm 0.82$ & $33.67 \pm 0.75$ & $33.76 \pm 0.81$ \\
\hline & Expressionless & female & $33.70 \pm 0.78$ & $33.72 \pm 0.87$ & $33.85 \pm 0.76$ & $33.94 \pm 0.79$ \\
\hline & & male & $33.77 \pm 0.73$ & $33.65 \pm 0.77$ & $33.75 \pm 0.66$ & $33.88 \pm 0.66$ \\
\hline
\end{tabular}


Table 2. Average HR and standard deviations during each period, each condition.

\begin{tabular}{|c|c|c|c|c|c|c|}
\hline \multirow[b]{2}{*}{$\begin{array}{l}\text { Status of } \\
\text { person }\end{array}$} & \multirow[b]{2}{*}{$\begin{array}{l}\text { Approaching } \\
\text { manner }\end{array}$} & \multirow[b]{2}{*}{$\begin{array}{l}\text { Sex of } \\
\text { person }\end{array}$} & \multicolumn{4}{|c|}{ Heart rate (bpm) } \\
\hline & & & $\mathrm{T}^{\mathrm{c}}$ (Baseline) & $\begin{array}{c}\mathrm{T}^{\mathrm{a}} \text { (2min later } \\
\text { after approaching) }\end{array}$ & $\begin{array}{l}\mathrm{T}^{\mathrm{a}, \mathrm{b}}(3 \text { min later } \\
\text { after } \mathrm{T} 2)\end{array}$ & $\begin{array}{c}\mathrm{T} 4^{\mathrm{b}, \mathrm{c}}(5 \mathrm{~min} \text { later } \\
\text { after } \mathrm{T} 3 \text { ) }\end{array}$ \\
\hline \multirow{5}{*}{ Familiar } & Smiling & female & $66.43 \pm 12.97$ & $100.54 \pm 28.28$ & $96.89 \pm 17.26$ & $77.06 \pm 14.21$ \\
\hline & & male & $69.86 \pm 11.17$ & $99.92 \pm 30.89$ & $89.69 \pm 17.90$ & $77.80 \pm 16.67$ \\
\hline & Expressionless & female & $66.57 \pm 8.30$ & $77.49 \pm 16.00$ & $83.22 \pm 18.67$ & $66.27 \pm 10.68$ \\
\hline & & male & $66.86 \pm 15.20$ & $97.21 \pm 47.62$ & $83.76 \pm 38.64$ & $86.66 \pm 23.80$ \\
\hline & & & $\mathrm{T} 1^{\mathrm{c}}$ & $\mathrm{T} 2^{\mathrm{a}}$ & $\mathrm{T} 3^{\mathrm{a}, \mathrm{b}}$ & $\mathrm{T} 4^{\mathrm{b}, \mathrm{c}}$ \\
\hline \multirow{4}{*}{ Unfamiliar } & Smiling & female & $87.82 \pm 20.58$ & $108.07 \pm 44.70$ & $106.91 \pm 36.60$ & $95.73 \pm 33.23$ \\
\hline & & male & $86.90 \pm 24.91$ & $121.70 \pm 47.95$ & $108.51 \pm 45.05$ & $96.07 \pm 38.31$ \\
\hline & Expressionless & female & $84.00 \pm 22.86$ & $107.42 \pm 38.57$ & $101.39 \pm 47.01$ & $88.32 \pm 26.52$ \\
\hline & & male & $82.58 \pm 21.33$ & $121.52 \pm 47.09$ & $111.80 \pm 45.68$ & $94.15 \pm 27.13$ \\
\hline
\end{tabular}

Letters ${ }^{\mathrm{a}, \mathrm{b}}$ and ${ }^{\mathrm{c}}$ indicate the significance within each category (Tukey, $\mathrm{P}<0.05$ ).

Stewart et al. reported a significant rise in eye-surface temperature 30 and $60 \mathrm{~min}$ after cows had been exposed to stimuli such as epinephrine, adrenocorticotrophic hormone, bovine corticotrophin-releasing hormone, or social isolation; the images were recorded every $2 \mathrm{~min}$ [8]. Travain et al. exposed a dog to stimuli for $20 \mathrm{~min}$; their recorded infrared thermographic images differed significantly between the pre-examination period and the period of examination by a veterinarian, and also between the examination and post-examination phases [2]. Nevertheless, there was no significant in our data. It may be difficult to discriminate the changes of both settings which familiar/unfamiliar person and which smiling/expressionless approach for dogs is. Or breed characteristics influenced our results. Vas et al. suggested that selective breeding may be more strongly influence the dogs' sensitivity to human social cues in different ways than sex differences [9], and Vas et al. also reported that behavioral traits of dogs were susceptible to environmental influences [10]. On the other hand, De Meester et al. demonstrated that the value of the socially acceptable behavior test as a temperament test of dogs, and they suggest that behavioral aspects are useful way to discuss their temperament and dogs' response to several stimuli are generalizable to daily life [11]. Thus, it may be the one which has to control both a background of the dogs or observational environment and estimate a physiological response to a familiar/unfamiliar person again. Moreover, it was not possible to confirm dramatic changes over this short period of time, and they need to be considered once again in a further study by examining short-term changes using a thermal video camera, as Riva et al. suggested [3].

Wells and Hepper reported that dogs housed in rescue shelters tended to stop barking earlier when a female approached than when a male approached [12]. The dogs might have expected a certain kind of reward (e.g. being spoken to in a gentle, high voice and stroked gently) when a female approached. Our former results have already suggested that a dog's behavioral response is influenced by the approach manner rather than by the sex of the approaching person, but neither factors affected eye temperature [5]. Our current eye-temperature results agree with these former results. During tests, the dogs seemed to have felt positive excitement at the approach of a female (as shown, for example, by increased frequency of tail wagging or panting; data not shown), but this did not affect their eye-surface temperatures.

Our recording of a significant rise in HR 2 min after the approaching person had stopped $70 \mathrm{~cm}$ from the dog suggested that HR could be used as an index for comparison with eye-surface temperature to check for early reactions. Palestrini et al. suggested that HR reacts predictably to stress or emotional stimuli [13]. Although temporal changes in HR were recorded in all the trials, the differences in HR among approach manners and among persons were not clear. In the smiling approach trials, the dog was wagging its tail and tried to move toward the approach person, thus pulling on the handler's lead. Thus the dog was excited by a smiling approach by a familiar person. However, this excitement did not cause physiological changes to the extent that eye-surface temperature increased. In the temporal changes in HR during this experiment, because a significant difference in HR was recorded after the approach (i.e. at T2) compared with T1 and T4, we consider that the sensitivity of HR to stimuli is high, and that $\mathrm{HR}$ is a useful index for judging real-time reactions. 
Dogs excel in social cognition in regard to humans; Miklósi et al. reviewed evidence that dogs could provide us with a wide range of information on behavioral flexibility across many social situations [14]. Beerda et al. reported that the reaction of the dog changes with the type of stimulus, but that HR normalizes from its peak at about the same time, regardless of the type of stimulus [7]. Dogs can notice either two-dimensional [15] [16] or three-dimensional [17] changes in human facial information and discriminate them. Therefore, in our experiment the approach by a human seemed to be recognized by the dog as a stimulus; in other words, the dog was likely influenced on a basic level by the approach of a human.

The results of our eye-surface temperature and HR evaluations of the reactions of dogs to two types of approach by people of two levels of familiarity suggest that the reaction times to each stimulus differ among indicators. This suggests that the dog slightly recognized whether the approach person was unfamiliar or familiar, although there was an individual difference. However, undeniably, the difference in reaction time between HR and eye temperature in response to stimulus disclosure may have influenced these results strongly. If eye temperature had been videotaped, then a different result might have been obtained. Therefore, to evaluate the reaction of a dog by using physiological indicators, it is necessary to take into consideration, and measure, the reaction time of each indicator. This individual influence on physiological markers needs to be investigated further in light of factors such as not only breed differences but also age, environment, and past experience.

\section{References}

[1] Vianna, D.M. and Carrive, P. (2005) Changes in Cutaneous and Body Temperature during and after Conditioned Fear to Context in the Rat. European Journal of Neuroscience, 21, 2505-2512. http://dx.doi.org/10.1111/j.1460-9568.2005.04073.x

[2] Travain, T., Colombo, S.E., Heinzl, E., Bellucci, D., Previde, P.E. and Valsecchi, P. (2015) Hot Dogs: Thermography in the Assessment of Stress in Dogs (Canis familiaris) - A Pilot Study. Journal of Veterinary Behavior, 10, 17-23. http://dx.doi.org/10.1016/j.jveb.2014.11.003

[3] Riva, J., Mareli, P.S., Redaelli, V., Sforzini, E., Luzi, F., Di Mari, W. and Verga, M. (2010) Video Infared Thermography Technique in Dogs. Journal of Veterinary Behavior, 5, 64-64. http://dx.doi.org/10.1016/i.jveb.2009.10.004

[4] Gauvin, V.D., Tilley, P.L., Smith, J.R.W.K.F. and Baird, J.T. (2006) Electrocardiogram, Hemodynamics, and Core Body Temperatures of the Normal Freely Moving Laboratory Beagle Dog by Remote Radiotelemetry. Journal of Pharmacology and Toxicology, 53, 128-139. http://dx.doi.org/10.1016/j.vascn.2005.11.004

[5] Fukuzawa, M., Kanaoka, K., Ema, T. and Kai, O. (2011) Effect of Approach Manner of an Unfamiliar Person on the Behavioural Action and Eye/ Ear Temperatures of Dogs (Canis familiaris). Proceedings of UFAW International Symposium, Portsmouth, 28-29 June 2011, 100.

[6] Knowles, T.G., Brown, S.N., Warriss, P.D., Phillips, A.J., Dolan, S.K., Hunt, P., Ford, J.E., Edwards, J.E. and Watkins, P.E. (1995) Effects on Sheep of Transport by Road for up to 24 Hours. Veterinary Record, 136, 431-438. http://dx.doi.org/10.1136/vr.136.17.431

[7] Beerda, B., Schilder, M.B.H., van Hooff, J.A.R.A.M., de Vries, H.W. and Mol, J.A. (1998) Behavioural, Saliva Cortisol and Heart Rate Responses to Different Types of Stimuli in Dogs. Journal of Applied Animal Behaviour Science, 58, 365-381. http://dx.doi.org/10.1016/S0168-1591(97)00145-7

[8] Stewart, M., Webster, J.R., Verkerk, G.A., Schaefer, A.L., Colyn, J.J. and Stafford, K.J. (2007) Non-Invasive Measurement of Stress in Dairy Cows Using Infrared Thermography. Physiology \& Behavior, 92, 520-525. http://dx.doi.org/10.1016/j.physbeh.2007.04.034

[9] Vas, J., Topál, J., Gácsi, M., Miklósi, Á. and Csányi, V. (2005) A Friend or an Enemy? Dogs’ Reaction to an Unfamiliar Person Showing Behavioural Cues of Threat and Friendliness at Different Times. Journal of Applied Animal Behaviour Science, 94, 99-115. http://dx.doi.org/10.1016/j.applanim.2005.02.001

[10] Vas, J., Topál, J., Gyõri, B. and Miklósi, Á. (2008) Consistency of Dogs’ Reactions to Threatening Cues of an Unfamiliar Person. Journal of Applied Animal Behaviour Science, 112, 331-344. http://dx.doi.org/10.1016/j.applanim.2007.09.002

[11] De Meester, H.R., Pluijmakers, J., Vermeire, S. and Laevens, H. (2011) The Use of the Socially Acceptable Behavior test in the Study of Temperament of Dogs. Journal of Veterinary Behavior, 6, 211-224. http://dx.doi.org/10.1016/j.jveb.2011.01.003

[12] Wells, D.L. and Hepper, P.G. (1999) Male and Female Dogs Respond Differently to Men and Women. Journal of Applied Animal Behaviour Science, 61, 341-349. http://dx.doi.org/10.1016/S0168-1591(98)00202-0

[13] Palestrini, C., Previde, E.P., Spiezio, C. and Verga, M. (2005) Heart Rate and Behavioural Responses of Dogs in the Ainsworth's Strange Situation: A Pilot Study. Journal of Applied Animal Behaviour Science, 94, 75-88. 
http://dx.doi.org/10.1016/j.applanim.2005.02.005

[14] Miklósi, Á., Topál, J. and Csányi, V. (2004) Comparative Social Cognition: What Can Dogs Teach us? Journal of Animal Behavior, 67, 995-1004. http://dx.doi.org/10.1016/j.anbehav.2003.10.008

[15] Guo, K., Meints, K., Hall, C., Hall, S. and Mills, D. (2009) Left Gaze Bias in Humans, Rhesus Monkeys and Domestic Dogs. Journal of Animal Cognition, 12, 409-418. http://dx.doi.org/10.1007/s10071-008-0199-3

[16] Racca, A., Amadei, E., Ligout, S., Guo, K., Meints, K. and Mills, D. (2010) Discrimination of Human and Dog Face and Inversion Responses in Domestic Dogs (Canis familiaris). Journal of Animal Cognition, 13, 525-533. http://dx.doi.org/10.1007/s10071-009-0303-3

[17] Fukuawa, M. and Kiyotoki, H. (2013) Dogs' Responses to Categorical Transformation of Human Faces. Journal of Animal Behaviour \& Management, 49, 113-121. 